\title{
Growth Stunting Implication in Children: A Review on Primary Tooth Eruption
}

\author{
Arlette S. Setiawan ${ }^{1}$ Nidia Abhista ${ }^{2}$ Prima Andisetyanto ${ }^{1}$ Ratna Indriyanti ${ }^{1}$ Netty Suryanti ${ }^{3}$ (i)
}

\author{
${ }^{1}$ Department of Pediatric Dentistry, Faculty of Dentistry, Universitas \\ Padjadjaran, Jl. Sekeloa Selatan 1, Bandung, Indonesia \\ 2 Faculty of Dentistry, Universitas Padjadjaran, Jl. Sekeloa Selatan 1, \\ Bandung, Indonesia \\ ${ }^{3}$ Department of Community Dentistry, Faculty of Dentistry, \\ Universitas Padjadjaran, Jl. Sekeloa Selatan 1, Bandung, Indonesia
}

Eur J Gen Dent 2022;11:7-16.

\begin{abstract}
Address for correspondence Arlette S. Setiawan, PhD, Department of Pediatric Dentistry, Universitas Padjadjaran Jl. Sekeloa Selatan 1 Bandung 40132, Indonesia (e-mail: arlette.puspa@fkg.unpad.ac.id).
\end{abstract}

\begin{abstract}
Keywords

- growth stunting

- tooth eruption

- deciduous teeth

Growth stunting is a form of malnutrition that causes children to have a shorter height for their age. Growth stunting can affect tooth eruption, including delayed deciduous teeth eruption. An electronic search was performed in PubMed and Google Scholar up to December 2020 including the terms related to eruption time of deciduous teeth in stunted children, articles in English and Indonesian, research on humans, research articles, and articles that can be accessed in full text. Articles that were not related to eruption time of deciduous teeth in stunted children, articles published over the last 10 years, articles that only used weight for age indicator as an indicator of malnutrition, and articles with incomplete pages were excluded from the study. Seven crosssectional articles were included in this study. Three studies assessed the age of deciduous teeth eruption, two studies assessed the number of erupted deciduous teeth in malnourished children, three studies assessed the sequence of deciduous teeth eruption, and six studies assessed the association of nutritional status with deciduous teeth eruption.
\end{abstract}

\section{Introduction}

Growth stunting has been diagnosed as the most common cause of malnutrition, a form of malnutrition measured using the indicator measuring height for age based on the World Health Organization (WHO) Child Growth Standards median. Children are classified as stunted if they are shorter than others at the same age group. Growth stunting causes children to have a shorter height for their age. According to the 2016 Global Nutrition Report, Indonesia is ranked 108 out of 132 countries based on growth stunting prevalence. Indonesia is one of 17 countries that experience a double burden of nutrition (overnutrition or undernutrition) and is also the country with the second highest prevalence of growth stunting in Southeast Asia. Based on the Basic Health

DOI https://doi.org/ $10.1055 / \mathrm{s}-0042-1742357$. ISSN 2320-4753.
Research (Riskesdas) results in 2018, the prevalence of growth stunting in Indonesia decreased by $6.4 \%$ within 5 years. In 2013, the prevalence of growth stunting in Indonesia was $37.2 \%$, and in 2018 , it decreased to $30.8 \% .^{1-3}$

The possible causes of growth stunting in Indonesia include direct factors (mother's nutritional status, breastfeeding practices, complementary feeding practices, and exposure to infection) and indirect factors (education, food system, health, and water and sanitation infrastructure and services). Growth stunting in children may have shortand long-term impacts, such as increased morbidity and mortality, poor child development and learning abilities, increased risk of infection and noncommunicable diseases in adulthood, and reduced productivity and economic Creative Commons Attribution License, permitting unrestricted use, distribution, and reproduction so long as the original work is properly cited. (https://creativecommons.org/licenses/by/4.0/)

Thieme Medical and Scientific Publishers Pvt. Ltd., A-12, 2nd Floor, Sector 2, Noida-201301 UP, India 
capacity. ${ }^{4}$ During development, malnutrition can affect oral structures. ${ }^{5,6}$ Lack of nutrients can cause damage to the enamel which contains higher levels of acidogenic bacteria so that it can facilitate the formation of caries. Nutritional deficiencies can also harm the quantity and quality of saliva, can affect the process of tooth eruption and tooth loss, and can affect the integrity of the soft tissues in the oral cavity. ${ }^{7}$

There is a very significant relationship between the age when the primary teeth erupt and the growth and development of children. ${ }^{8}$ Estimation of the eruption time of teeth is an essential tool in determining the planning of children's dental health, including diagnostic, preventive, and therapeutic steps in the field of pediatric dentistry and orthodontics. ${ }^{9}$ Tooth eruption is the process of tooth movement from formation in the alveolar bone to the occlusal plane in the oral cavity. ${ }^{10}$ Several variables can affect the eruption of primary teeth, including race, socioeconomic status, and nutritional status. ${ }^{8}$

Chronic malnutrition affects tooth development that causes hypoplasia and delayed eruption of primary teeth. ${ }^{11}$ There is a significant relationship between poor nutritional status and delayed tooth eruption reported in several studies in India. ${ }^{5}$ Delayed eruption of primary teeth due to malnutrition and growth stunting had a stronger relationship with delayed tooth appearance than wasting. Other studies also showed that growth stunting and poor nutritional status caused fewer teeth to erupt at 6 and 12 months. There was no evidence of prematurity associated with the pattern of tooth eruption. However, in a study conducted by Delgado-Angulo et al, eruption changes in the primary and permanent teeth were not found in their study of stunted children in Peru. ${ }^{7}$

From the results of previous studies, there is a limited systematic literature review that discusses the description of tooth eruption in stunted children, so that this study aims to identify the description of the eruption time of primary teeth in stunted children.

\section{Methods}

In this study, the Author uses a literature study method with a systematic approach, using the Preferred Reporting Items for Systematic Reviews and Meta-Analyses (PRISMA) method. The research was conducted from February to April 2021 by accessing national and international articles obtained from PubMed and Google Scholar.

\section{Search Strategy}

From PubMed and Google Scholar databases, article searches were performed using keywords ("tooth eruption" OR "tooth emergence") AND ("primary tooth" OR “deciduous tooth" OR "primary dentition") AND ("malnutrition" OR "growth stunting" OR "undernutrition"). The inclusion criteria in this study were national and international articles published in the last 10 years (2010-2020), articles related to the description of the eruption time of primary teeth in stunted children, articles in English and Indonesian, human studies, research articles, and articles which can be fully accessed in full text. Articles that only used the weight for age indicator as an indicator of malnutrition and articles with incomplete pages were excluded.

\section{Article Selection}

Article selection was performed in two stages; the first stage was performed after reading the title and abstract, and the second stage was after reading the article as a whole. First, the articles were excluded from the study if the article did not meet the inclusion or exclusion criteria. Then, the results of the selection of articles are written in the PRISMA diagram.

\section{Article Quality Assessment}

Quality assessment systematically assesses and interprets evidence by considering research results' validity, results, and relevance. Assessment of the quality of articles used in this study is the National Institute of Health (NIH) Study Quality Assessment Tools. The Quality Assessment Tool for Observational Cohort and Cross-Sectional Studies, consisting of 14 question criteria, was used to assess articles with a cross-sectional study design. Each included article was assigned a good-, fair-, or poor-quality rating by two reviewers who assessed the quality of the articles in this study.

\section{Data Extraction and Data Synthesis}

Data extraction was performed by reading all the articles that had been selected, and the corresponding data were recorded for each in a table containing the authors' data, article title, journal name, year, keywords, study design, sample size, country, assessment, results, conclusion, and journal quality. Data synthesis is done by making connections between all the articles read to answer research questions from the review. ${ }^{12}$ In this research, the data synthesis used is thematic synthesis. Thematic synthesis is based on thematic analysis where thematic synthesis uses a similar type of analysis to unite and integrate the findings of several qualitative studies into systematic reviews. ${ }^{13}$

\section{Result}

Based on the results of article searches that have been performed through two databases, PubMed and Google Scholar, 56 articles were obtained on PubMed and 648 articles on Google Scholar. Of the 704 articles, duplicate articles were removed, so that 564 articles were obtained. Then, the articles were screened based on the title and abstract. A total of 505 articles were excluded from the study, and 59 articles were obtained which were then assessed in full text. Of the 59 articles, 52 were not used in the study because they were included in the exclusion criteria after a full-text assessment. A total of seven articles were included in this study. Study selection results are recorded in the PRISMA diagram (-Fig. 1). 


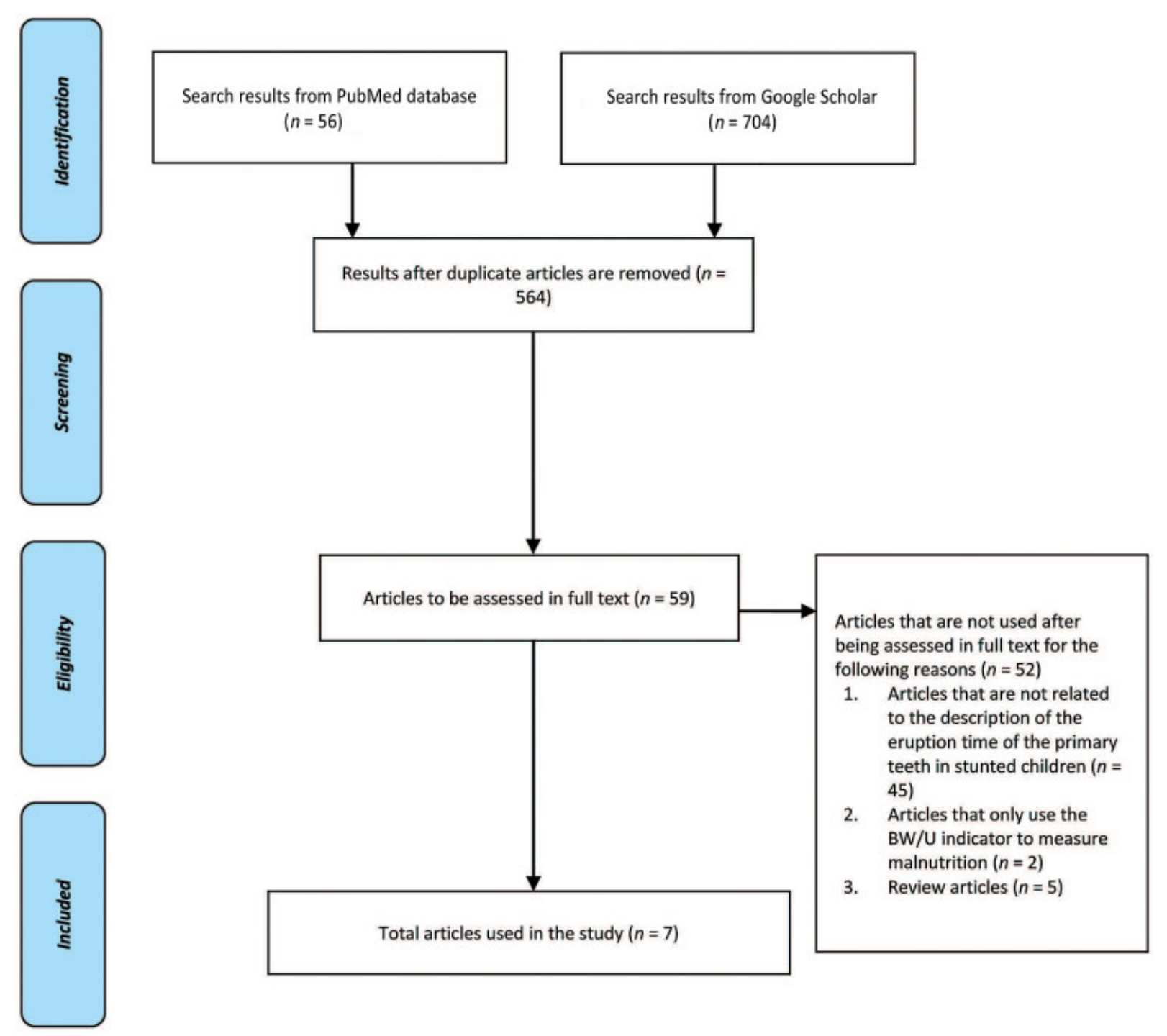

Fig. 1 Selection result recorded in the Preferred Reporting Items for Systematic Reviews and Meta-Analyses (PRISMA).

\section{Quality Assessment}

Of the seven articles included in this study, one article had good quality, four articles had moderate quality, and two articles had poor quality. Articles with good quality have a low risk of bias, while articles with poor quality have a high risk of bias. The results of the article quality assessment can be seen in - Table 1.

\section{Article Characteristics}

The articles used in this study have the same study design. The seven articles are studies with a cross-sectional study design. All studies were conducted in the Asian continent. Two of the studies were conducted in India, two were conducted in Iraq, one was conducted in Jordan, one was conducted in Iran, and the other was conducted in Indonesia (-Table 2 ).

\section{Age of Eruption of Primary Teeth}

Three studies assessed the age of eruption of the primary teeth. One of them assessed the eruption time of the first primary teeth. The age of appearance of primary teeth in children in Jordan which were grouped into underweight (UW), average weight (NW), overweight (OW), short stature (SS), average stature (NS), and tall stature (TS). ${ }^{14}$ The mean age of eruption of the primary teeth was also assessed in other studies on children with good nutritional status (standard) and children with poor nutritional status (growth stunting). ${ }^{15,16}$

\section{Number of Deciduous Teeth that Have Erupted}

An assessment was made of the number of erupted primary teeth in growth stunting, UW, wasting, and severely malnourished children in India from birth to 48 months. ${ }^{17}$ Another study that also assessed the average number of erupted primary teeth in well-nourished and malnourished children in Iraq. ${ }^{18}$

\section{The Sequence of Eruption of Primary Teeth}

The order of eruption of the primary teeth was assessed by three studies (-Table $\mathbf{3}$ ). One study was conducted in India, 
Table 1 Articles' quality

\begin{tabular}{|c|c|c|c|c|c|c|c|c|c|c|c|c|c|c|c|c|}
\hline \multirow[t]{8}{*}{ Assessor 1} & Author & $\mathrm{C} 1$ & $\mathrm{C} 2$ & $\mathrm{C} 3$ & $\mathrm{C} 4$ & C5 & C6 & C7 & $\mathrm{C} 8$ & C9 & C10 & C11 & C12 & C13 & C14 & $\begin{array}{l}\text { Article } \\
\text { quality }\end{array}$ \\
\hline & Gaur and Kumar ${ }^{17}$ & Yes & Yes & - & Yes & Yes & - & - & Yes & Yes & - & Yes & - & - & - & Medium \\
\hline & Singh et al ${ }^{1}$ & Yes & Yes & - & Yes & Yes & - & - & Yes & Yes & - & Yes & - & - & - & Medium \\
\hline & Hanoon $^{18}$ & Yes & Yes & - & Yes & - & - & - & Yes & Yes & - & Yes & - & - & - & Poor \\
\hline & $\begin{array}{l}\text { Shaweesh and } \\
\text { Al-Batayneh }\end{array}$ & Yes & Yes & Yes & Yes & - & - & - & Yes & Yes & - & Yes & - & - & Yes & Good \\
\hline & Vejdani et a ${ }^{16}$ & Yes & Yes & - & Yes & - & - & - & Yes & Yes & - & Yes & - & - & Yes & Medium \\
\hline & $\begin{array}{l}\text { Amalliah } \\
\text { Badruddin et al }\end{array}$ & Yes & Yes & - & Yes & - & - & - & Yes & Yes & - & Yes & - & - & - & Poor \\
\hline & Ali et al & Yes & Yes & - & Yes & Yes & - & - & Yes & Yes & - & Yes & - & - & - & Medium \\
\hline \multirow[t]{7}{*}{ Assessor 2} & Gaur and Kumar ${ }^{17}$ & Yes & Yes & - & Yes & Yes & - & - & Yes & Yes & - & Yes & - & - & - & Medium \\
\hline & Singh et al ${ }^{1}$ & Yes & Yes & - & Yes & Yes & - & - & Yes & Yes & - & Yes & - & - & - & Medium \\
\hline & Hanoon $^{18}$ & Yes & Yes & - & Yes & - & - & - & Yes & Yes & - & Yes & - & - & - & Poor \\
\hline & $\begin{array}{l}\text { Shaweesh and } \\
\text { Al-Batayneh }\end{array}$ & Yes & Yes & Yes & Yes & - & - & - & Yes & Yes & - & Yes & - & - & Yes & Good \\
\hline & Vejdani et a ${ }^{16}$ & Yes & Yes & - & Yes & - & - & - & Yes & Yes & - & Yes & - & - & Yes & Medium \\
\hline & $\begin{array}{l}\text { Amalliah } \\
\text { Badruddin et al }^{15}\end{array}$ & Yes & Yes & - & Yes & - & - & - & Yes & Yes & - & Yes & - & - & - & Poor \\
\hline & Ali et al ${ }^{19}$ & Yes & Yes & - & Yes & Yes & - & - & Yes & Yes & - & Yes & - & - & - & Medium \\
\hline
\end{tabular}

one was conducted in Jordan, and another was conducted in Indonesia. Shaweesh and Al-Batayneh assessed the order of appearance of primary teeth in 1,756 children aged 1 to 33 months who were grouped into three weight groups, that is, UW, NW, and OW, and three height groups, that is, SS, NS, and TS. $^{14}$ Gaur and Kumar also assessed the sequence of eruption of the primary teeth in stunted, UW, wasting, and severely malnourished children. Assessment is performed on boys and girls. ${ }^{17}$ Amalliah Badruddin et al also assessed the eruption pattern of primary teeth in children in Beji District. ${ }^{15}$

\section{Relationship of Nutritional Status with Eruption of Primary Teeth}

Six of seven articles with a cross-sectional study design assessed the relationship between nutritional status and the eruption of primary teeth. Singh et al assessed the delay in the pattern of tooth eruption that occurs in normal, growth stunting, and UW children. ${ }^{1}$ Amalliah Badruddin et al assessed the average age of primary tooth eruption and its relationship to nutritional status and sociodemographic factors. ${ }^{15}$ Ali et al assessed the number of erupted primary teeth and their relationship to the $z$-score of height for age. ${ }^{19}$ Gaur and Kumar, Shaweesh and Al-Batayneh, and Vejdani et al also conducted a review of the relationship between height and weight with the appearance of deciduous teeth. ${ }^{14,16,17}$

\section{Discussion}

Tooth eruption can be influenced by several factors, including genetics, hormonal factors, gender, race, craniofacial morphology, nutrition and growth parameters, as well as height and weight. ${ }^{9}$ From the results of this study, four studies assessed the relationship between height and weight with the appearance of primary teeth. Gaur and Kumar stated that height correlates better with the number of deciduous teeth that have emerged than body weight. This can occur due to a strong relationship between tooth eruption and skeletal growth. ${ }^{17}$ However, in the research results conducted by Shaweesh and Al-Batayneh, bodyweight shows a stronger relationship with tooth appearance, especially in the maxillary canines, lateral incisors, and central incisors. ${ }^{14}$

Growth stunting is determined by measuring body length (supine for children under 2 years of age) or height (height when standing for children aged 2 years or older) and comparing them with traditional values. ${ }^{20}$ From the results of research conducted by Vejdani et al showed that children aged 3 to 15 months in Rasht, Iran, experienced a delay in the eruption of their primary teeth and that the height/age index was associated with the eruption of the first deciduous teeth in boys, but there was no relationship in girls. ${ }^{16}$ A similar statement was made by Ali et al in his research on children aged 4 to 48 months in Iraq, where the results showed that the $z$-score of length or height for age and weight for age had a partial correlation with the number of deciduous teeth that had erupted and showed children with greater height and weight have more teeth than other children. Based on the results of this study, it can be interpreted that normal children with better nutrition have more teeth and earlier tooth eruption. ${ }^{19}$

The height, weight, and head circumference of a child are related to nutrition. The results of Vejdani et al showed that the eruption of primary teeth could indicate the nutritional status of children. ${ }^{16}$ The results of research conducted by 


\begin{tabular}{|c|c|c|c|}
\hline & \begin{tabular}{|l}
$\frac{E}{\bar{y}}$ \\
$\frac{\bar{d}}{2}$
\end{tabular} & $\frac{\underline{\underline{\underline{n}}}}{\frac{\underline{\underline{m}}}{2}}$ & ఏ \\
\hline 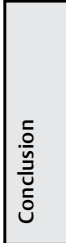 & 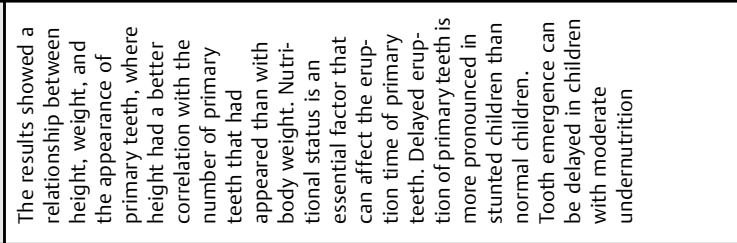 & 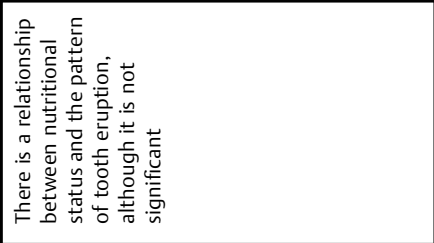 & 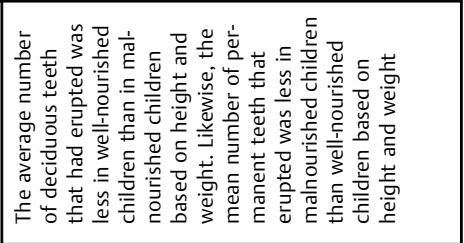 \\
\hline 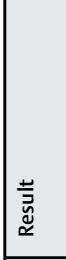 & 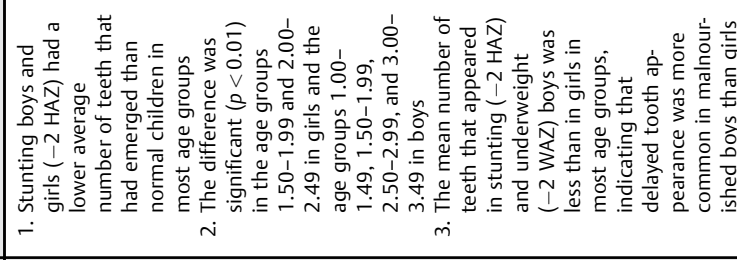 & 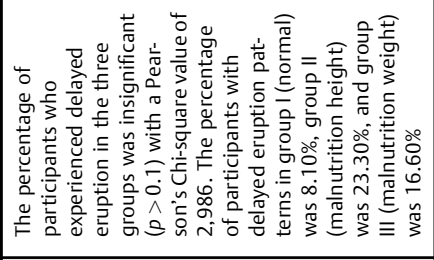 & 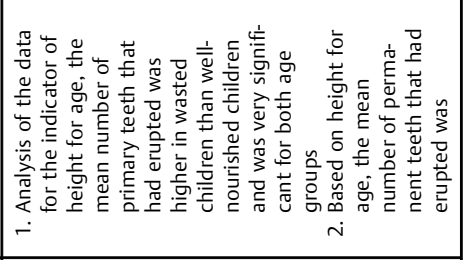 \\
\hline 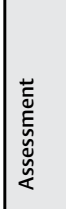 & 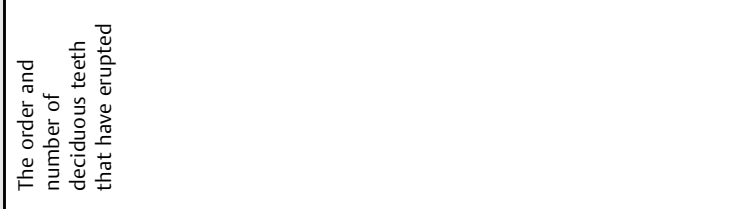 & 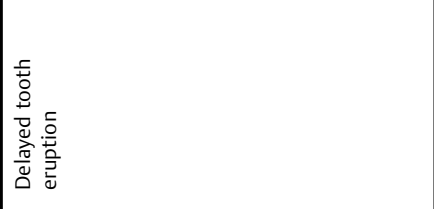 & 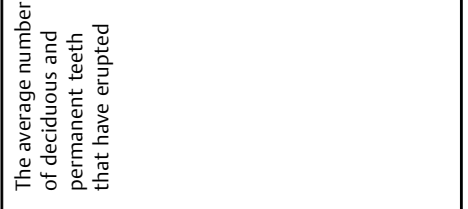 \\
\hline 苇 & 尊 & 疍 & $\underset{\underline{\underline{\sigma}}}{\underline{\sigma}}$ \\
\hline & 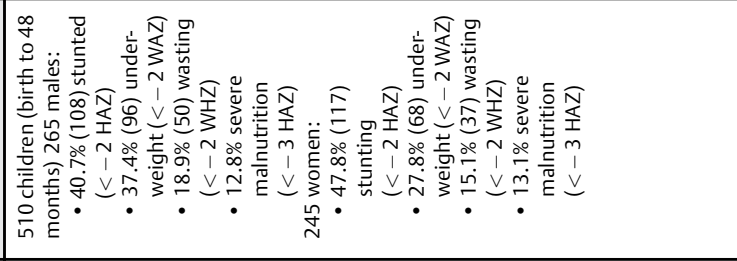 & 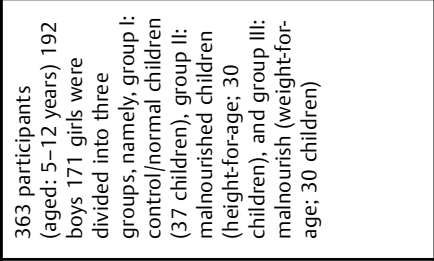 & 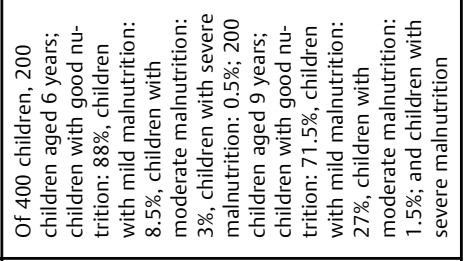 \\
\hline 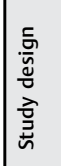 & 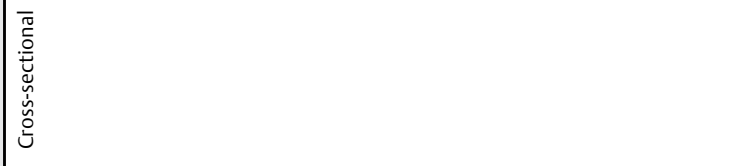 & & 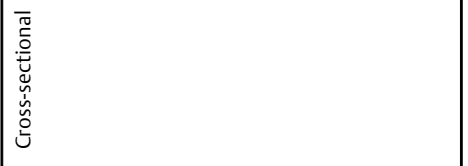 \\
\hline 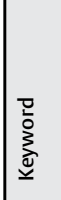 & 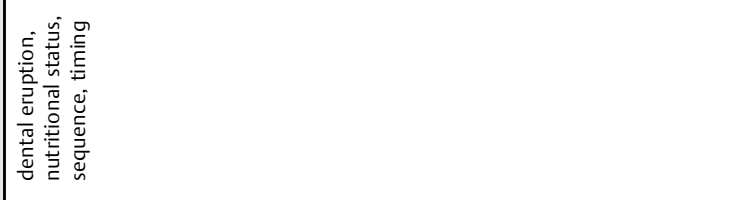 & 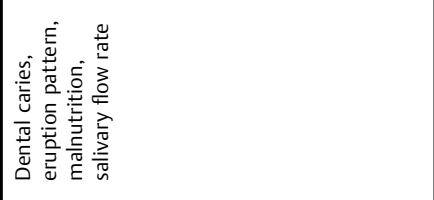 & . \\
\hline 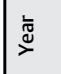 & ָे & $\stackrel{\infty}{\stackrel{\infty}{2}}$ & 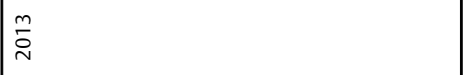 \\
\hline 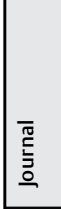 & 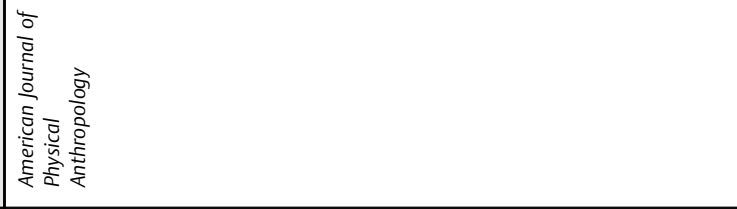 & 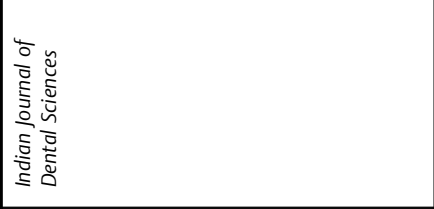 & 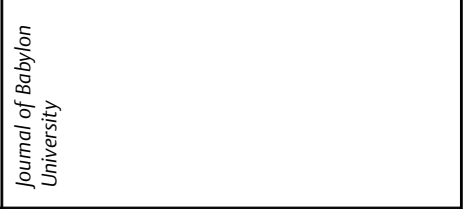 \\
\hline 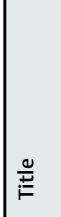 & 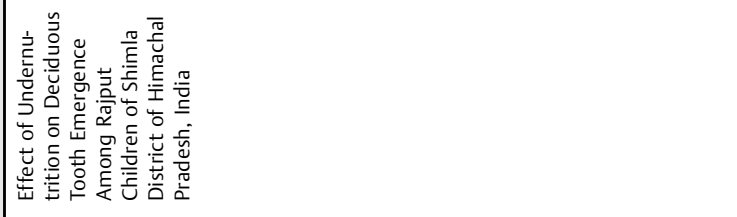 & 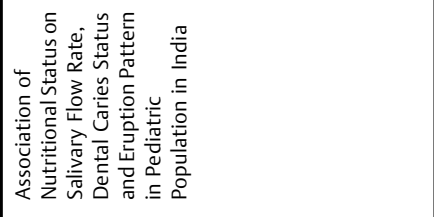 & 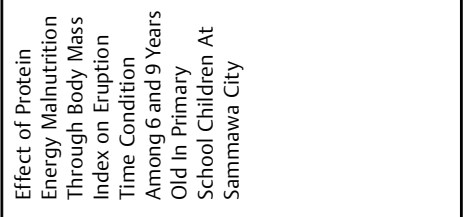 \\
\hline 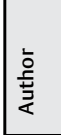 & 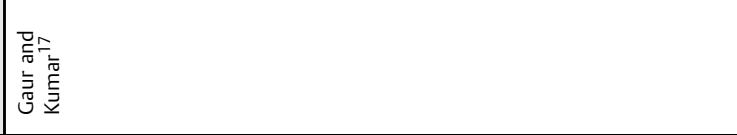 & 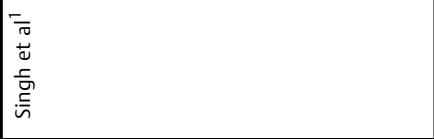 & 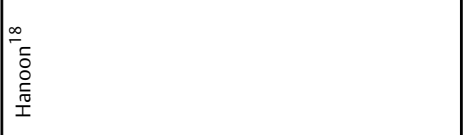 \\
\hline$\frac{\delta}{2}$ & - & $\sim$ & m \\
\hline
\end{tabular}




\begin{tabular}{|c|c|c|}
\hline 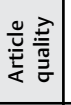 & & : \\
\hline & & 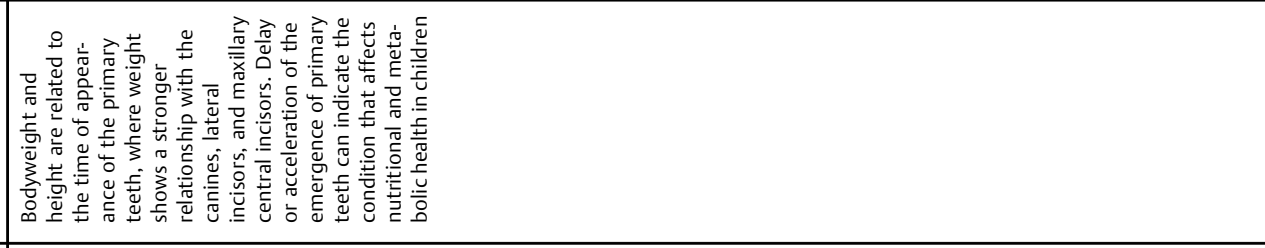 \\
\hline 這 & 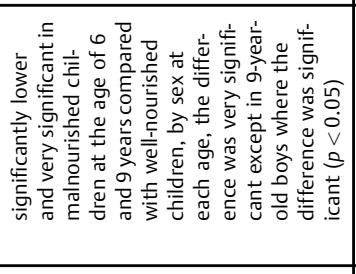 & 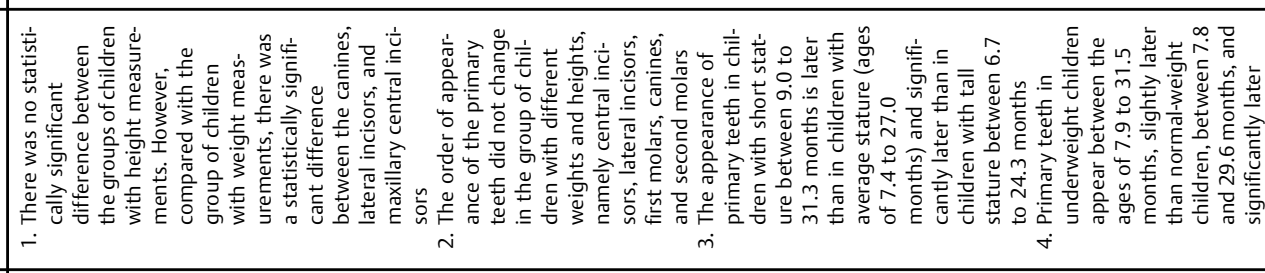 \\
\hline 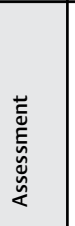 & & 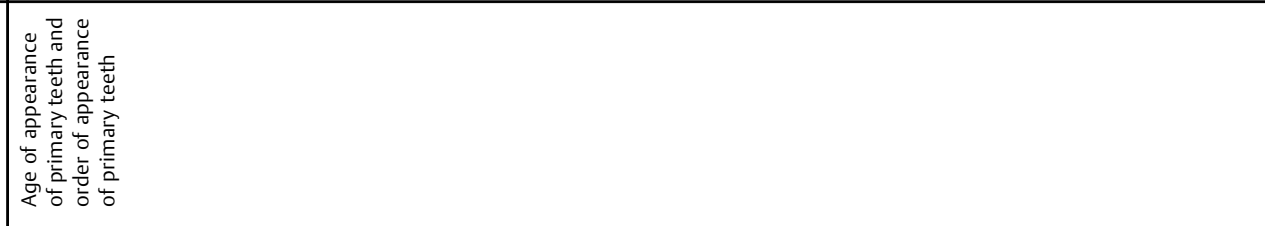 \\
\hline 竧 & & \\
\hline & & 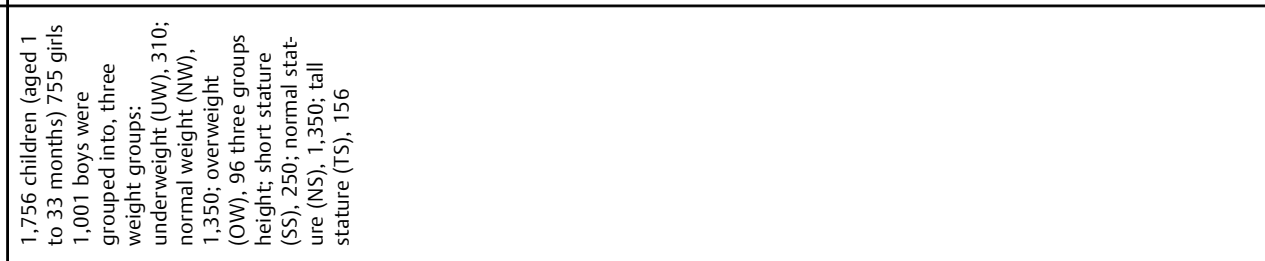 \\
\hline 点 & & \\
\hline & & 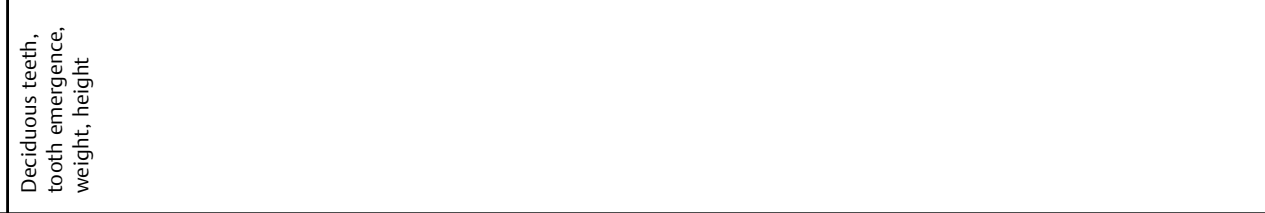 \\
\hline$\stackrel{\bar{\Xi}}{\check{\Xi}}$ & & 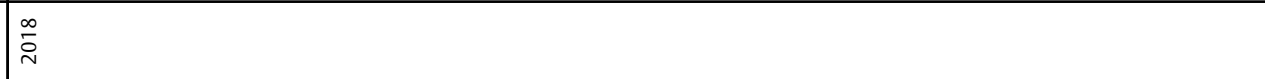 \\
\hline 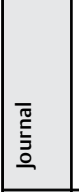 & & 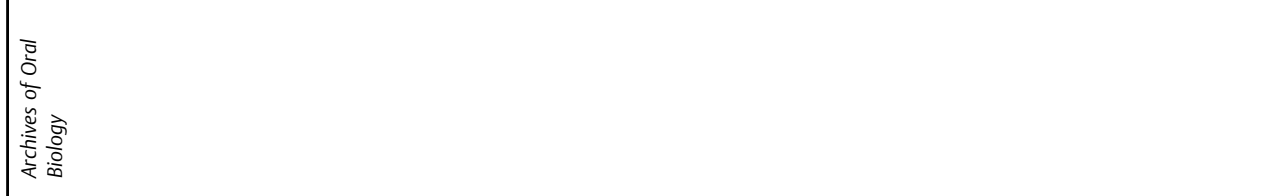 \\
\hline 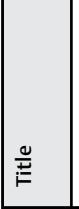 & & 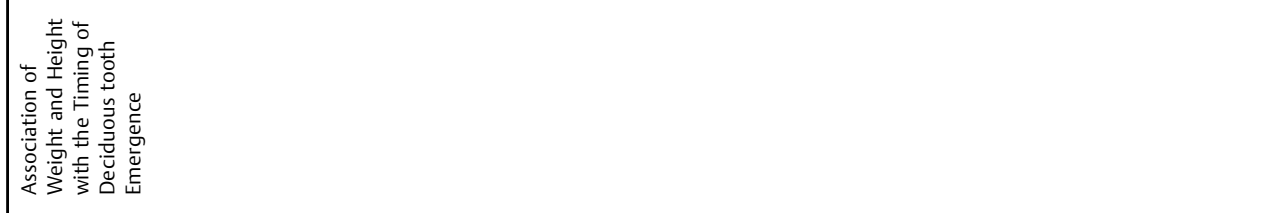 \\
\hline 高 & & 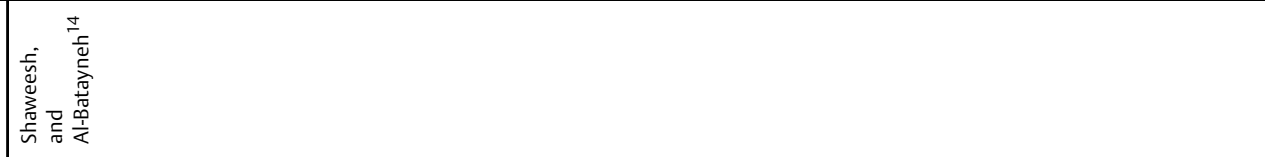 \\
\hline$\dot{s}$ & & + \\
\hline
\end{tabular}




\begin{tabular}{|c|c|c|c|}
\hline 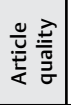 & & $\mid \frac{\underline{\underline{n}}}{\frac{5}{2}}$ & 六 \\
\hline & & 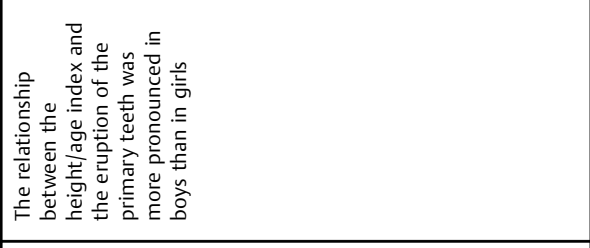 & 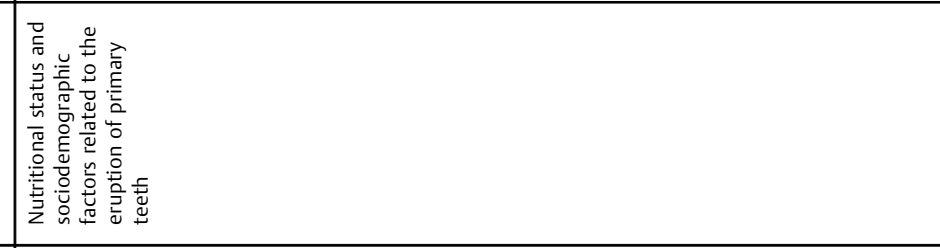 \\
\hline 訔 & 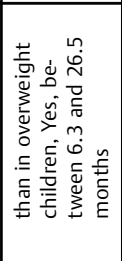 & 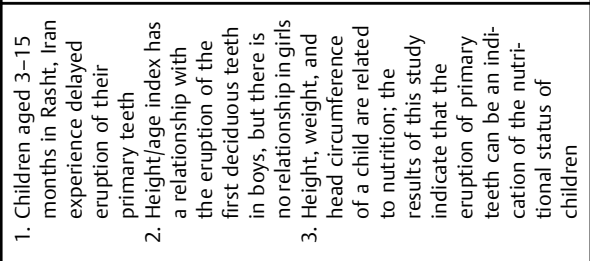 & 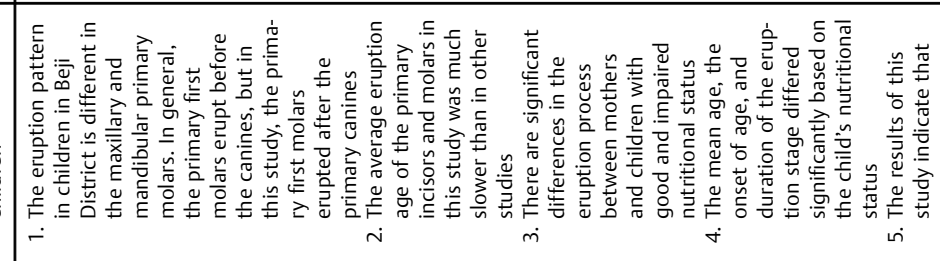 \\
\hline 䓂 & & 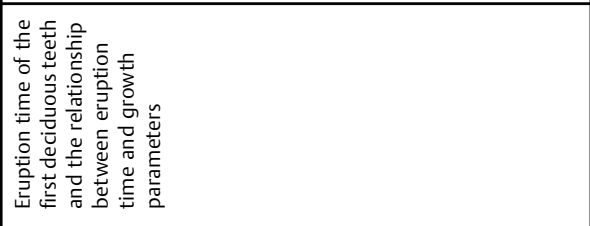 & 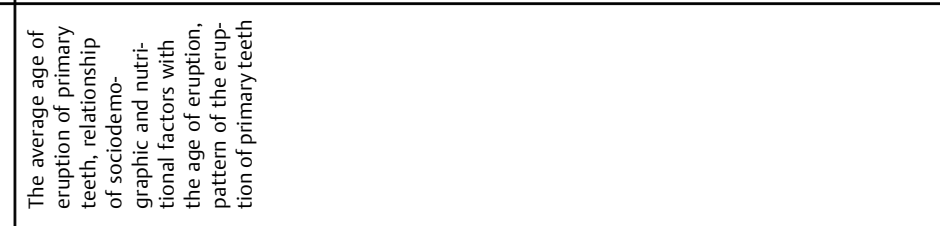 \\
\hline 訔 & & $\underline{\underline{\underline{\underline{\underline{e}}}}}$ & 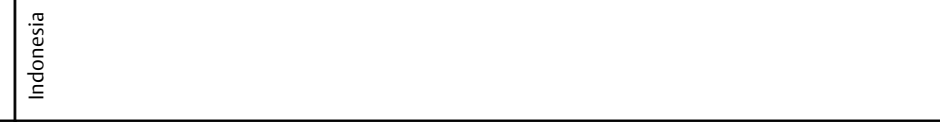 \\
\hline & & 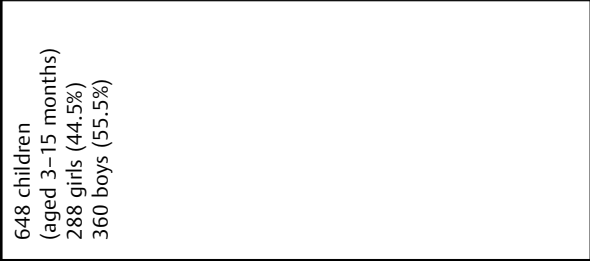 & 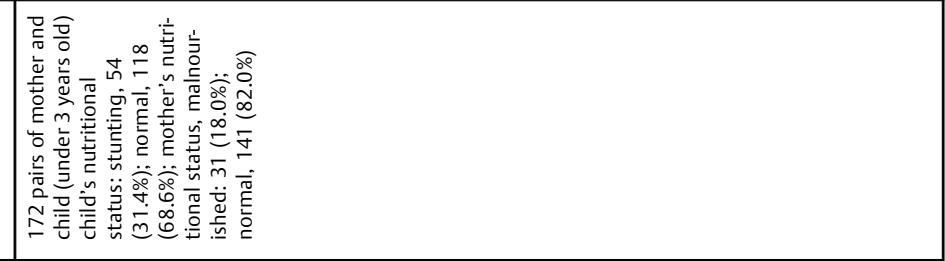 \\
\hline 童 & & 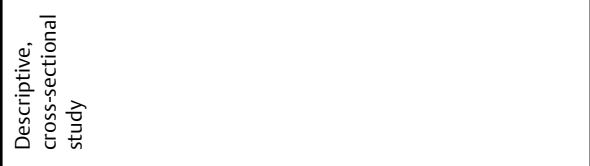 & 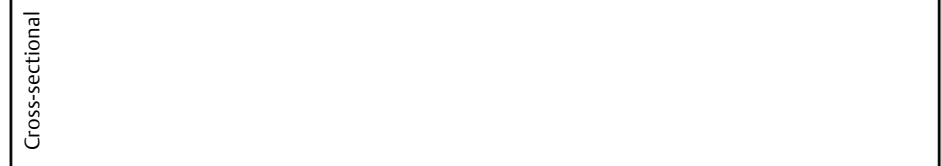 \\
\hline & & 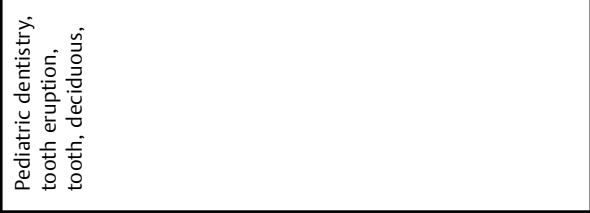 & 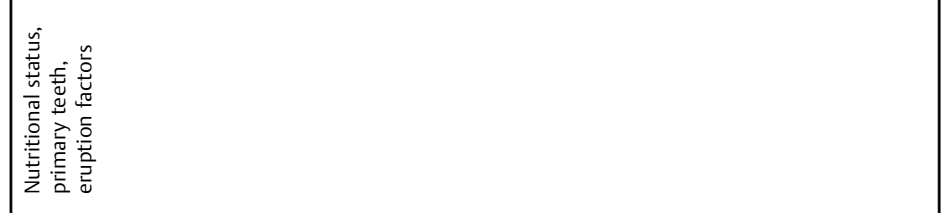 \\
\hline 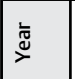 & & 吕 & 产 \\
\hline 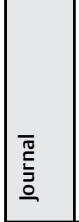 & & 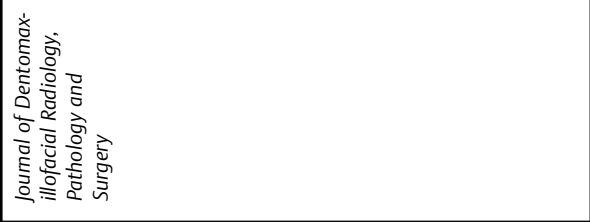 & 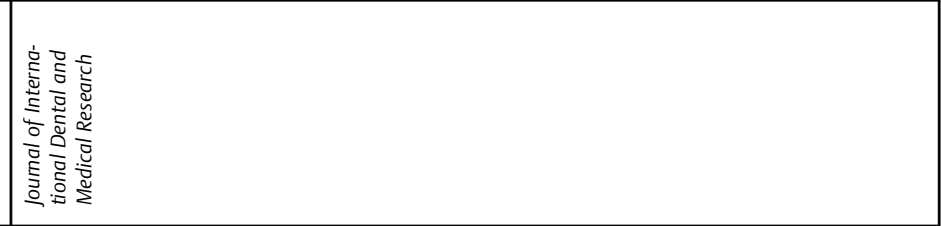 \\
\hline$\stackrel{\Xi}{\rightleftarrows}$ & & 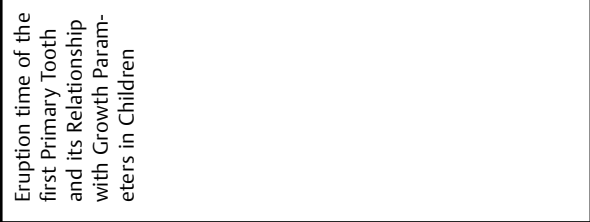 & 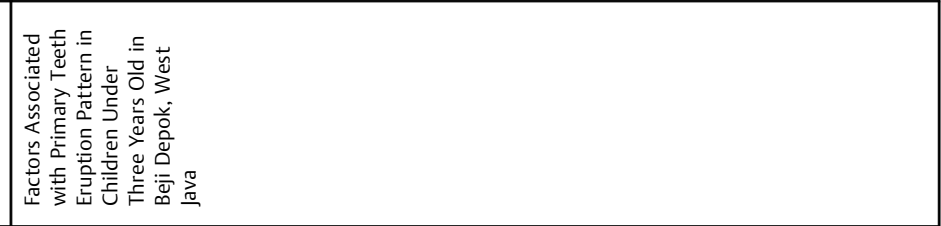 \\
\hline 高 & & 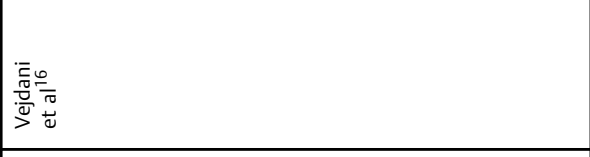 & 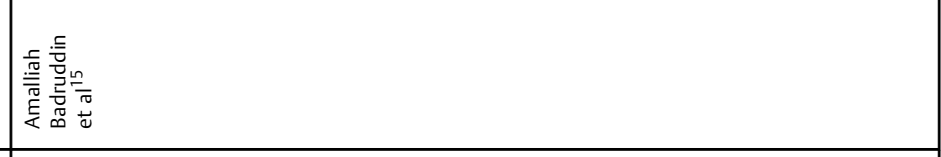 \\
\hline$\dot{\dot{z}}$ & & in & 0 \\
\hline
\end{tabular}




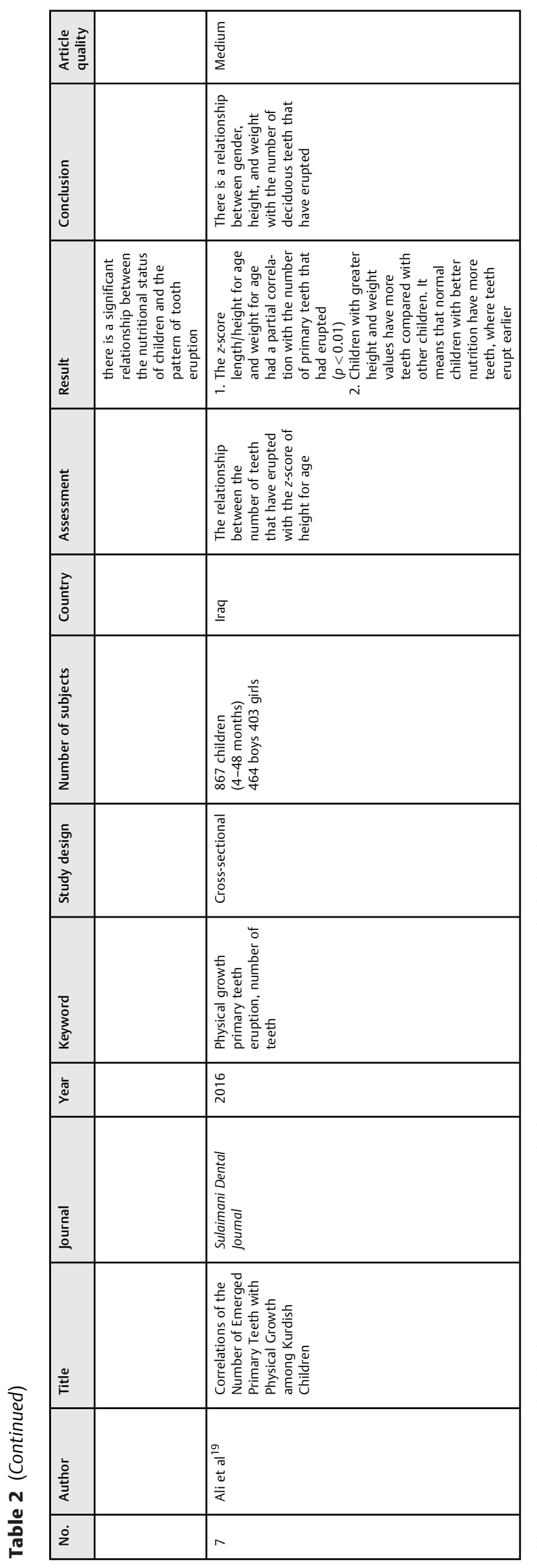

Amalliah Badruddin et al showed a significant relationship between the nutritional status of children and the eruption pattern of the primary teeth. His research also states significant differences in the eruption process between mothers and children who have good nutritional status and mothers and children who have poor nutritional status (growth stunting). The research results by Amalliah Badruddin et al showed that the average age of eruption of incisors and primary molars was much slower than other studies. ${ }^{15}$ However, in contrast to the research results conducted by Singh et al in India. In his research, Singh et al stated a relationship between nutritional status and the pattern of tooth eruption, although it is not significant. ${ }^{1}$

Growth stunting in toddlers can affect the eruption time of primary teeth and increase the risk of caries. ${ }^{6}$ The results of the assessment of the study on the age of appearance of the primary teeth in children with SS showed that the deciduous teeth appeared in children with SS later than in children with NS and much later than in children with TS. These results were obtained from research conducted by Shaweesh and Al-Batayneh in children from 1 to 33 months of age in Jordan who were grouped into three height groups based on the Centers for Disease Control and Prevention (CDC): The United States height-forage growth charts. The primary teeth in children of SS appear at 9.0 to 31.3 months of age. While in children with NS, primary teeth appear between the ages of 7.4 to 27.0 months, and in children with TS, deciduous teeth appear between the ages of 6.7 and 24.3 months. $^{14}$

Two of the seven articles reviewed in this study assessed the number of erupted primary teeth in malnourished children. In the research Gaur and Kumar, children with malnutrition are grouped into three groups, namely, growth stunting, UW, and wasting, based on WHO standards. The number of deciduous teeth that have erupted in stunted children as studied by Gaur and Kumar on children in India showed that growth-stunting children ( -2 height-for-age $z$ score [HAZ]), both boys and girls, had an average number of teeth that appeared less than normal children in most age groups and had a significant difference $(p<0.01)$ in girls in the age group of 1.50 to 1.99 and 2.00 to 2.49 years and in boys, age groups between 1.00 to $1.49,1.50$ to $1.99,2.50$ to 2.99 , and 3.00 to 3.49 years. The average number of teeth erupted in stunted ( $-2 \mathrm{HAZ}$ ) and UW ( -2 weight-for-age $z$-score [WAZ]) boys compared with girls in most age groups. This result shows that the delay in the appearance of teeth is more common in malnourished boys than girls. ${ }^{17}$

Meanwhile, children with low weight-for-height z-score (WHZ) or wasting showed varying patterns, whereas girls with low WHZ from the age of 0.5 to 3 years showed an average number of teeth that appeared less than regular girls. In contrast to the assessment results on boys under 1.5 years of age with low WHZ, they showed more teeth than regular boys. ${ }^{17}$ Similar results were reported by a study conducted by Hanoon on malnourished children in Iraq. Hanoon showed that the average number of deciduous teeth erupted in wasted children was more than that of well-nourished children and was very significant in both age groups. An assessment of the average number of erupted permanent 
Table 3 Primary dentition sequence of eruption

\begin{tabular}{|c|c|c|c|c|}
\hline \multirow{4}{*}{$\begin{array}{l}\text { Sequence of } \\
\text { tooth } \\
\text { eruption }\end{array}$} & \multicolumn{4}{|l|}{ Author } \\
\hline & \multicolumn{2}{|l|}{ Gaur and $\mathrm{Kumar}^{17}$} & \multirow[t]{2}{*}{ Shaweesh and Al-Batayneh $^{14}$} & \multirow[t]{2}{*}{ Amalliah Badruddin et al } \\
\hline & Boys & Girls & & \\
\hline & $\begin{array}{l}\text { Upper central incisors } \\
\text { Lower central incisors } \\
\text { Upper lateral incisors } \\
\text { Lower lateral incisors } \\
\text { Upper first molars } \\
\text { Lower first molars } \\
\text { Upper canine } \\
\text { Lower canine } \\
\text { Lower second molars } \\
\text { Upper second molars }\end{array}$ & $\begin{array}{l}\text { Lower central incisors } \\
\text { Upper central incisors } \\
\text { Upper lateral incisors } \\
\text { Lower lateral incisors } \\
\text { Upper first molars } \\
\text { Lower first molars } \\
\text { Upper canine } \\
\text { Lower canine } \\
\text { Lower second molars } \\
\text { Upper second molars }\end{array}$ & $\begin{array}{l}\text { Lower central incisors } \\
\text { Upper central incisors } \\
\text { Upper lateral incisors } \\
\text { Lower lateral incisors } \\
\text { Upper first molars } \\
\text { Lower first molars } \\
\text { Lower canine } \\
\text { Upper canine } \\
\text { Upper second molars } \\
\text { Lower second molars }\end{array}$ & $\begin{array}{l}\text { Upper central incisors } \\
\text { Lower lateral incisors } \\
\text { Upper lateral incisors } \\
\text { Upper canine } \\
\text { Lower central incisors } \\
\text { Lower canine } \\
\text { Lower first molars } \\
\text { Upper first molars } \\
\text { Upper second molars } \\
\text { Lower second molars }\end{array}$ \\
\hline
\end{tabular}

teeth was also performed in the study by Hanoon. Malnourished children have an average number of permanent teeth that erupt less than children who have good nutrition. ${ }^{18}$

The eruption order of the primary teeth assessed in two studies did not show any change in the eruption order, namely, central incisors, lateral incisors, first molars, canines, and second molars. ${ }^{14,17}$ The results of this study are similar to the results of previous studies conducted by Al-Batayneh et al in a cross-sectional study that assessed the timing and order of appearance of primary teeth in Jordan. Al-Batayneh et al stated that the order of appearance of the primary teeth in the maxilla and mandible were central incisors, lateral incisors, first molars, canines, and second molars. ${ }^{21}$ However, it was found that there were differences in eruption patterns in children in Beji District in a study conducted by Amalliah Badruddin et al. In this study, the primary first molars erupted after the primary canines. ${ }^{15}$

Delay in the pattern of tooth eruption was found in the regular group of children, the group of malnourished children based on height for age (growth stunting), and also in the group of malnourished children based on weight for age (UW) in the results of a study conducted by Singh et al. The highest percentage of children with delayed tooth eruption was found in malnourished children based on height for age or growth stunting children. ${ }^{1}$ However, in his study, it was not explained whether the assessment of the delay in tooth eruption was performed on the eruption of primary teeth or permanent teeth. The results of this study are consistent with the results in a review article which states that chronic malnutrition in early childhood is correlated with delayed tooth eruption. ${ }^{22}$ Chronic malnutrition can occur due to a lack of carbohydrates, proteins, and fats. Lack of macronutrients, such as protein deficiency, can affect the growth and development of teeth, one of which is the delay in tooth eruption. Proteins needed by the body include binding iodine, forming thyroid hormones, and as an iodine transporter. Protein and iodine are nutrients needed in the process of tooth eruption. Iodine that binds to tyrosine can affect the formation of osteoblasts which then stimulates the formation of osteoclasts so that tooth eruption can occur. Therefore, tooth eruption disorders can occur when the body lacks protein intake. Lack of micronutrients, such as calcium and vitamins C, A, D, and E, can also slow down the process of tooth eruption. ${ }^{15}$

\section{Limitations}

The limitation of this study is that all articles included in this study have a cross-sectional study design, where this crosssectional study design is at a low level in evidence-based medicine. The results of the article quality assessment also showed that only one article had good quality, four articles had moderate quality, and the other two had poor quality. Articles of poor quality indicate that they have a high risk of bias. The authors hope that further research can conduct clinical research on the description of the eruption time of primary teeth in stunted children accompanied by radiographic examination to strengthen the research results.

\section{Conclusion}

Nutritional status has a relationship with the eruption of primary teeth. From the results obtained, it can be concluded that the eruption time of the primary teeth in stunted children is delayed and can be seen from the number of deciduous teeth that have erupted less in stunted children, slower tooth emergence in children with SS, and delayed tooth eruption found in stunted children. In addition, there are variations in the eruption sequence of the primary teeth in stunted children.

\section{Conflict of Interest \\ None declared.}

\section{Acknowledgment}

The authors wish to thank Universitas Padjadjaran for the Academic Leadership Grant that funded this study.

\section{Reference}

1 Singh N, Bansal K, Chopra R, Kaur Dharmani C. Association of nutritional status on salivary flow rate, dental caries status and eruption pattern in the pediatric population in India. Indian J Dent Sci. 2018;10(02):72-82 
2 Kartini A, Suhartono S, Subagio HW, Budiyono B, Emman IM. Kejadian stunting dan kematangan usia tulang pada anak usia sekolah dasar di daerah pertanian Kabupaten Brebes. J Kesehat Masy 2016;11(02):96-103

3 Sholecha RP, Yunitasari E, Armini NKA, Arief YS. Analisis Faktor yang berhubungan dengan Pencegahan Stunting pada Anak Usia 2-5 Tahun berdasarkan Teori Health Promotion Model (HPM). Pediomaternal Nurs J. 2019;5(01):49

4 Beal T, Tumilowicz A, Sutrisna A, Izwardy D, Neufeld LM. A review of child stunting determinants in Indonesia. Matern Child Nutr 2018;14(04):e12617

5 Sheetal A, Hiremath VK, Patil AG, Sajjansetty S, Kumar SR. Malnutrition and its oral outcome - a review. J Clin Diagn Res 2013;7(01):178-180

6 Sadida ZJ, Indriyanti R, Setiawan AS. Does growth stunting correlate with oral health in children?: a systematic review Eur J Dent 2021 (e-pub ahead of print). Doi: 10.1055/s-0041-1731887

7 Delgado-Angulo EK, Hobdell MH, Bernabe E. Childhood stunting and caries increment in permanent teeth: a three and half year longitudinal study in Peru. Internat J Paediatr Dent 2013;23:101-109

8 Alnemer KA, Pani SC, Althubaiti AM, Bawazeer M. Impact of birth characteristics, breast feeding and vital statistics on the eruption of primary teeth among healthy infants in Saudi Arabia: an observational study. BMJ Open 2017;7(12):e018621

9 Poureslami H, Asl Aminabadi N, Sighari Deljavan A, et al. Does timing of eruption in first primary tooth correlate with that of first permanent tooth? A 9-years cohort study. J Dent Res Dent Clin Dent Prospect 2015;9(02):79-85

10 Rahmawati AD, Retriasih H, Medawati A. Hubungan antara Status Gizi dengan Status Erupsi Gigi Insisivus Sentralis Permanen Mandibula. Idj. 2014;3(01):16-21

11 Dimaisip-Nabuab J, Duijster D, Benzian H, et al. Nutritional status, dental caries and tooth eruption in children: a longitudinal study in Cambodia, Indonesia, and Lao PDR. BMC Pediatr 2018;18(01):300
12 Ridley D. The Literature Review A Step by Step Guide for Students. 2nd ed. London, United Kingdom: SAGE Publications; 2012:232

13 Booth A, Sutton A, Papaioannou D. Systematic Approaches to a Successful Literature Review. Second Edi. SAGE Publications. London, United Kingdom: SAGE Publications; 2016:336

14 Shaweesh AIA, Al-Batayneh OB. Association of weight and height with timing of deciduous tooth emergence. Arch Oral Biol 2018; 87:168-171

15 Amalliah Badruddin I, Putri MR, Rahardjo A, Badruddin IA, Putri MR, Rahardjo A. Factors associated with primary teeth eruption pattern in children under three years old in Beji Depok, West Java. J Int Dent Med Res. 2017;10(Special Issue):564-568

16 Vejdani J, Javaneh V, Abtin H, Darkhaneh E, Mohammad S. Eruption time of the first primary tooth and its relationship with growth Parameters in children. Pathol Surg. 2015;3(04): 15-19

17 Gaur R, Kumar P. Effect of undernutrition on deciduous tooth emergence among Rajput children of Shimla District of Himachal Pradesh, India. Am J Phys Anthropol 2012;148(01):54-61

18 Hanoon SA. Effect of protein-energy malnutrition through body mass index on eruption time condition among 6 and 9 years old in primary school children at Sammawa City. J Babylon Univ Appl Sci. 2013;21(06):1-9

19 Ali D, Muhammad N, Noori A, Kareem F. Correlations of the number of emerged primary teeth with physical growth among Kurdish children. Sulaimani Dent J. 2016;3(01):52-57

20 de Onis M, Branca F. Childhood stunting: a global perspective. Matern Child Nutr 2016;12(1, suppl 1):12-26

21 Al-Batayneh OB, Shaweesh AI, Alsoreeky ES. Timing and sequence of emergence of deciduous teeth in Jordanian children. Arch Oral Biol 2015;60(01):126-133

22 Alshukairi $\mathrm{H}$. Delayed tooth eruption and its pathogenesis in a pediatric patient: a review. J Dent Health Oral Disord Ther 2019; 10(03):209-212 